\title{
HEMOLYTIC ANEMIA IN FEMALES: AN UNEXPECTED CAUSE
}

\author{
Marcela de Oliveira Pires, Filipa Forjaz Cirurgião, Melissa Brigham Figueiredo, Rita Monteiro. \\ Department of Pediatrics, São Francisco Xavier Hospital, Lisboa Ocidental Centro Hospital, Lisbon, \\ Portugal.
}

\begin{abstract}
Glucose-6-phosphate dehydrogenase (G6PD) deficiency is the most common enzymopathy and is inherited as an X-linked trait, therefore homozygotic females are rare. We present a five-year-old girl, who had severe hemolytic anemia after fava beans ingestion and an infectious insult. Investigations revealed G6PD deficiency associated with a genetic A- variant, which was also present in both her father and brother.
\end{abstract}

\author{
ARTICLE HISTORY \\ Received 6 March 2021 \\ Accepted 26 March 2021

\begin{abstract}
KEYWORDS
Glucose phosphate

Dehydrogenase deficiency, Female, Homozygote, Genes X-Linked, Anemia Hemolytic, Congenital
\end{abstract}

\section{Introduction}

Glucose-6-phosphate dehydrogenase (G6PD) deficiency is the most common enzymopathy, affecting more than 400 million people worldwide. ${ }^{1,2}$ G6PD has an important role in protection against red cells oxidative damage. 2,3,4 The enzyme catalyzes pentose phosphate's pathway first step - oxidation of glucose-6-phosphate to 6-phosphogluconolactone and the reduction of NADP+ to NADPH. ${ }^{3,4} \mathrm{NADPH}$ maintains a high level of reduced glutathione, protecting hemoglobin against hydrogen peroxide and other oxygen radicals. . $^{3,4}$ The G6PD gene is located on the long arm of the $X$ chromosome. ${ }^{5}$ These gene mutations are related to protein variants with different levels of enzyme activity and an wide range of clinical phenotypes. ${ }^{1}$ The most common clinical manifestations are hemolytic anemia and neonatal jaundice, triggered by an oxidative stress exposure (such as drugs, food or infections).1,3,6 Some variants are related to chronic hemolysis and congenital nonspherocytic hemolytic anemia. ${ }^{1,3,6}$ G6PD is inherited as an X-linked trait ${ }^{3,7}$, therefore homozygotic females are rarer than hemizygous males 5 and have similar clinical manifestations.

We report the case of a girl with homozygotic G6PD deficiency that presented with severe hemolytic anemia. We discuss G6PD variants, different clinical phenotypes and emphasize the importance of considering this disorder in females.

\section{Case Report}

A previously healthy five-year-old female of Brazilian origin presented to the emergency department with fatigue, headache and chest pain evolving over a 7-day period. On the day of admission, she started vomiting

Address for Correspondance: Marcela de Oliveira, Department of Pediatrics, Hospital de São Francisco Xavier, Centro Hospitalar de Lisboa Ocidental, Rua Pio XII, n. 8, $2^{\circ}$ esquerdo, 2700-657 Pires, Amadora, Lisbon, Portugal.

Email: anamarcelapires@gmail.com

(C2021 Pediatric Oncall and had fever. There was no relevant family history, and she had ingested fava beans on the first day of symptoms. There was no intake of other relevant food or drugs. On examination she was prostrated, with pale skin and conjunctiva, and had tachycardia and a systolic murmur (grade II/VI). Blood work revealed severe hemolytic anemia (Table 1). Auto immune, infectious etiology and hemoglobinopathies were excluded (Table 2). Abdominal ultrasound was unremarkable. Erythrocyte G6PD activity was in the lower limit of the reference range (Table 2 ). The child was admitted and received red blood cell transfusion on the first day without complications. Throughout the hospitalization, there was remarkable improvement, with no fever and resolution of the complaints. Hemoglobin values progressively increased and hemolysis parameters normalized. She was discharged on day 6 and was kept on regular follow-up. After 3 months, erythrocyte G6PD activity test showed moderate enzymatic deficiency $(0.8 \mathrm{U} / \mathrm{gHb}-11 \%)$. Genetic testing was then pursued which revealed c.202G $>A$ (exon 4) and c.376A $>G$ (exon 5) modifications resulting in p.(Val68Met) and p.(Asn126Asp) amino acids replacement, compatible with homozygotic G6PD A- variant. Family genetic testing revealed G6PD deficiency in her father and brother; her mother had normal enzymatic activity. Her brother has the same variant. Two years after the diagnosis, she avoids food and drugs causing oxidative stress, remains asymptomatic and with no reports of further hemolytic episodes.

\section{Discussion}

The World Health Organization classifies G6PD variants according to magnitude of enzyme deficiency and hemolysis severity. ${ }^{7,8}$ Class I variants are rare and have severe enzyme deficiency ( $<10 \%$ activity) with chronic hemolysis. Class II variants, such as the Mediterranean variant, are also associated to severe deficiency but present with acute hemolytic anemia. Class III variants (including the A-variant) result in moderate deficiency (10 to $60 \%$ activity), causing intermittent hemolysis. Classes IV and $V$ have no clinical significance. ${ }^{8}$ The Mediterranean variant causes more severe anemia 
Table 1. Blood investigations of the patient

\begin{tabular}{|c|c|c|c|c|}
\hline & Admission & After RBCT & At discharge & 3 months later \\
\hline $\begin{array}{l}\text { Erythrocytes ( } \times 10^{12} \text { cells/cumm) } \\
\text { RR: 3.9-5.3 }\end{array}$ & 1.72 & 2.94 & 3.25 & 4.57 \\
\hline $\begin{array}{l}\text { Hemoglobin }(\mathrm{g} / \mathrm{dL}) \\
\text { RR: } 11.5-13.5\end{array}$ & 4.7 & 8.3 & 9 & 12 \\
\hline $\begin{array}{l}\text { Hematocrit (\%) } \\
\text { RR: } 34-40\end{array}$ & 14.6 & 25.8 & 29 & 37.4 \\
\hline $\begin{array}{l}\text { Mean corpuscular hemoglobin (fL) } \\
\text { RR: } 25-29\end{array}$ & 27.5 & 28.2 & 27.8 & 26.3 \\
\hline $\begin{array}{l}\text { Mean corpuscular volume (fL) } \\
\text { RR: } 75-87\end{array}$ & 85.2 & 87.7 & 89.2 & 81.8 \\
\hline $\begin{array}{l}\text { RDW (\%) } \\
\text { RR: } 11.5-14.5\end{array}$ & 15.7 & 16 & 17.5 & 13.7 \\
\hline $\begin{array}{l}\text { Reticulocytes }\left(\% / \times 10^{9} / \mathrm{L}\right) \\
\text { RR: } 0.5-2 / 20-100\end{array}$ & $7.3 / 126$ & - & $16.3 / 530$ & $1.8 / 80$ \\
\hline $\begin{array}{l}\text { Platelets }\left(\times 10^{9} / \mathrm{L}\right) \\
\text { RR: } 200-450\end{array}$ & 357 & 350 & 357 & 258 \\
\hline Peripheral blood smear & $\begin{array}{l}\text { Mild anisocytosis and } \\
\text { polychromatophilia }\end{array}$ & - & - & Unremarkable \\
\hline $\begin{array}{l}\text { Haptoglobin }(\mathrm{mg} / \mathrm{dL}) \\
\text { RR: } 26-185\end{array}$ & $<10$ & - & 43 & 71 \\
\hline $\begin{array}{l}\text { Total bilirubin }(\mathrm{mg} / \mathrm{dL}) \\
\text { RR: }<1\end{array}$ & 2.07 & - & 0.16 & 0.31 \\
\hline Direct bilirubin $(\mathrm{mg} / \mathrm{dL})$ & 0.48 & - & - & - \\
\hline $\begin{array}{l}\text { Lactate dehydrogenase (U/L) } \\
\text { RR: } 135-225\end{array}$ & 1133 & - & - & 244 \\
\hline Urinalysis & Positive hemoglobin & - & - & - \\
\hline
\end{tabular}

Note: RR - Reference range, RBCT - Red blood cell transfusion

Table 2. Investigations for autoimmune disorders and infectious agents

\begin{tabular}{ll}
\hline Test & Result \\
\hline Direct and indirect Coomb's test & Negative \\
Complement C3 (mg/dL) & 148 \\
RR: $90-180$ & \\
Complement C4 (mg/dL) & 36.3 \\
RR: $10-40$ & \\
Immunoglobulin A (mg/dL) & 86.1 \\
RR: $26-232$ & \\
Immunoglobulin G (mg/dL) & 1150 \\
RR: $560-1307$ & \\
Immunoglobulin M (mg/dL) & 88.2 \\
RR: $56-242$ & Negative \\
Anti-Parvovirus B19 antibodies (IgM) & Negative \\
Anti-Mycoplasma pneumoniae antibodies (IgM) & Negative \\
Anti-Cytomegalovírus antibodies (IgM) & Negative \\
Anti-Epstein-Barr antibodies (IgM) & 4.6 \\
Erythrocyte G6PD (U/g) & \\
RR: $4.6-13.5$ & Unremarkable \\
Hemoglobin electrophoresis and quantification of Hb A2 and Hb F & \\
\hline
\end{tabular}

Note: RR - Reference range 
compared to A- (more common in Africa and other regions, such as Brazil) ${ }^{2}$, which is usually associated to self-limited and mild anemia. ${ }^{9}$ More than 186 variants are identified in addition to the wild-type G6PD gene. The majority are missense mutations causing single amino acid replacement. ${ }^{5}$

G6PD deficient homozygotic females are rare and have clinical manifestations that are similar to those of heterozygotic males. In this case the patient presented with severe hemolysis which is not the most frequent phenotype associated to the identified variant $\left(A^{-}\right)$. The severe presentation is likely related to exposure to more than one agent known to trigger oxidative stress; fava beans intake (causing prolonged hemolysis which is corroborated by reticulocytosis) and an infectious insult. G6PD deficiency must be consider in the differential diagnosis of hemolytic anemia with negative Coomb's test in females, even in the absence of suggestive personal or family history. The diverse variants and phenotypes have a broad spectrum of severity. Therefore, there are many undiagnosed individuals with mild symptoms or even asymptomatic.

When diagnosing G6PD deficiency is essential to properly interpretate the normal reference range of G6PD activity. In severe hemolysis there is an increase of enzymatic activity due to the presence of reticulocytes and young red blood cells, which often leads to a false negative result, as described in this case report. ${ }^{1,9,10}$ Enzymatic activity should be repeated 2 to 3 months after the acute episode to confirm or exclude the diagnosis of G6PD deficiency. ${ }^{10}$ Genetic studies to identify the variant is crucial, since it has prognostic implications and identifies those who require genetic counseling. 4,8

\section{Compliance with Ethical Standards}

Funding: None

Conflict of Interest: None

\section{References:}

1. Cappellini MD, Fiorelli G. Glucose-6-phosphate dehydrogenase deficiency. Lancet. 2008;371:64-74.

2. Mason PJ, Bautista JM, Gilsanz F. G6PD deficiency: the genotype-phenotype association. Blood Rev. 2007;21:267283.

3. Mehta A, Mason PJ, Vulliamy TJ. Glucose-6-phosphate dehydrogenase deficiency. Best Pract Res Clin Haematol. 2000;13:21-38.

4. Ronquist G, Theodorsson E. Inherited, non-spherocytic haemolysis due to deficiency of glucose-6-phosphate dehydrogenase. Scand J Clin Lab Invest. 2007;67:105111.

5. Luzzatto L, Nannelli C, Notaro R. Glucose-6-Phosphate Dehydrogenase Deficiency. Hematol Oncol Clin North Am. 2016;30:373-393.

6. Beutler E. G6PD: Population genetics and clinical manifestations. Blood Rev. 1996;10:45-52.

7. Hsia YE, Miyakawa F, Baltazar J, Ching NS, Yuen J, Westwood B, Beutler E. Frequency of glucose-6-phosphate dehydrogenase (G6PD) mutations in Chinese, Filipinos, and Laotians from Hawaii. Hum Genet. 1993;92:470-476.

8. WHO Working Group. Glucose-6-phosphate dehydrogenase deficiency. Bull World Health Organ. 1989;67:601-611.

9. Beutler E. G6PD deficiency. Blood. 1994;84:3613-3636.

10. Roper D, Layton M, Rees D, Lambert C, Vulliamy T, De la Salle B, D'Souza C; British Society for Haematology. Laboratory diagnosis of G6PD deficiency. A British Society for Haematology Guideline. Br J Haematol. 2020;189:2438. 